\title{
Environmental impacts and certification: evidence from the Milan World Expo 2015
}

Article

Accepted Version

Guizzardi, A., Mariani, M. and Prayag, G. (2017)

Environmental impacts and certification: evidence from the Milan World Expo 2015. International Journal of Contemporary Hospitality Management, 29 (3). pp. 1052-1071. ISSN 09596119 doi: https://doi.org/10.1108/IJCHM-09-2015-0491 Available at https://centaur.reading.ac.uk/70260/

It is advisable to refer to the publisher's version if you intend to cite from the work. See Guidance on citing.

To link to this article DOI: http://dx.doi.org/10.1108/IJCHM-09-2015-0491

Publisher: Emerald

All outputs in CentAUR are protected by Intellectual Property Rights law, including copyright law. Copyright and IPR is retained by the creators or other copyright holders. Terms and conditions for use of this material are defined in the End User Agreement.

\section{www.reading.ac.uk/centaur}

\section{CentAUR}

Central Archive at the University of Reading 
Reading's research outputs online 


\title{
Environmental Impacts and Certification:
}

\section{Evidence from the Milan World Expo 2015}

\begin{abstract}
Purpose - This study examines residents' perceptions of environmental impacts and certification for the Milan World Expo 2015 as well as their overall attitude towards the mega event.
\end{abstract}

Design/methodology/approach - A survey of Milan residents based on a convenience sample of residents in Milan led to 221 useable questionnaires.

Findings - Residents perceived that the Expo will have minimal negative and positive environmental impacts. A minority of residents were aware of the environmental certification of the event. The less agreeable residents were with the perceived negative environmental impacts of the event, the more agreeable they were that a certification of event sustainability should limit the damage to the natural environment. Residents' perceptions of the certification were positively related to their overall attitude towards the event.

Research limitations/implications - The findings cannot be generalized to other mega events but have several managerial implications in relation to the need for information provision to residents and better communication of the certification by event organizers and planners.

Originality/value - Despite rising concerns about environmental issues related to hosting mega events, there is no research on perceptions of a certification of event sustainability by residents.

Keywords: Mega-event, Expo 2015, environmental certification, environmental impacts, resident attitude

Paper type Research paper 


\section{Introduction}

Sustainable event management (also known as event greening) refers to the staging of an event with particular concern for environmental impacts. Despite a number of sporting events using event greening over the last two decades (e.g., the Lillehammer Olympic Organizing Committee received the UNEP Global 500 Award for setting environmental standards), environmental certifications have only recently appeared as a way to manage environmental impacts. The 2012 London Olympics was the first mega sporting event to be endowed with a Certification for Event Sustainability (CES). According to Müller's (2015) criteria for classification of events, the Milan World Expo 2015 is a mega-event due to its number of visitors (22 million tickets sold), cost (6 billion Euros) and capital investment (14-18 billion Euros) (Mincuzzi, 2015). The World Expo 2015 is the first Universal Exposition with a CES that complies with the international standard of ISO 20121 due to its environmental management system. The theme of the World Expo 2015, "Feeding the Planet, Energy for Life", revolves mainly around environmental sustainability. Literature on the role of CES in managing event impacts is virtually absent (Case, 2013; Getz and Page, 2016; Holmes et al., 2015). Indeed, most of the existing studies on event impacts have prioritized economic (e.g. Case et al., 2010) at the expense of socio-cultural and environmental impacts (Davies et al., 2013; Getz and Page, 2016; Holmes et al., 2015). Accordingly, the aims of this study are two-fold. First, we investigate residents' perceptions of the environmental impacts of the Milan World Expo 2015 as well as their awareness and perceptions of the CES. Second, we examine if residents' perceptions of event impacts and environmental certification can predict their overall attitude towards the event.

The study contributes to the tourism and events literature in three main ways. First, the relationship between residents' perceptions of a CES and perceptions of environmental impacts for a mega-event has been sparsely investigated. From a theoretical point of view, understanding residents' perceptions of a CES broadens the scope of environmental impact research in the events literature while also providing a knowledge base for events managers and policy makers to understand the effectiveness of a CES among local communities. A CES is often communicated as part of the overall 
communication strategy of an event, disregarding its effectiveness on events' stakeholders, including residents. Existing studies mainly examine residents' perceptions of the environmental impacts of events (Lorde et al., 2011; Prayag et al., 2013) or methods for estimating actual environmental impacts (Collins et al., 2009). Second, in line with the well accepted triple bottom line approach (Ellkington, 1997), we examine perceived positive and negative environmental impacts separately. Several studies (Chen and Tian, 2015; Lorde et al., 2011; Zhou and Ap, 2009) either group the positive/negative environmental impacts with other positive/negative economic and/or social impacts or make no distinction between different types of impacts. These approaches often mask the specific influence of environmental impacts or different types (positive and negative) of environmental impacts. Third, the influence of both perceived positive and negative environmental impacts on overall attitude towards the event is evaluated. The terms 'attitude' and 'support' have been used interchangeably in the literature (Ko and Stewart, 2002; Zhou and Ap, 2009) but a psychometric difference exists between the two constructs as identified in previous studies (Prayag et al., 2013).

\section{Events Sustainability}

\section{The Concept of Sustainability and Sustainable Tourism}

According to the UN World Commission on Environment and Development, sustainable development is defined as "... development that meets the needs of the present without compromising the ability of future generations to meet their own needs (UNEP, 1987). Sustainability is a highly contested term with several meanings in the literature. The need for ecological and environmental sustainability coexists with ideas of social and economic goals that meet human needs in an equitable manner (Callicott and Mumford, 1997; Williams and Millington, 2004). A distinction is often made between weak and strong sustainability on the basis that the former focuses on resources management for future generations while the latter emphasizes the need to reduce consumption altogether (Williams and Millington, 2004). It is therefore of no surprise that there is limited agreement on the formulation, meaning and subsequent operationalization of the term 'sustainable tourism' (Garrod 
and Fyall, 1998; Hardy et al., 2002). Three dimensions of sustainable tourism namely economic, social and environmental are recognized in the literature (Saarinen, 2006) but the role of sociocultural aspects in the development of sustainability have been less studied (Hardy et al., 2002). Sustainability has also found its way into the events literature through the concept of "sustainable events". In particular, the sustainability of mega-events has been questioned (Hall, 2012) and event organizers criticized for equity and fairness concerns, environmental integrity, local population displacement, as well as the lack of wider participation of local communities in the decision making processes (Bramwell, 1997). The legacy of mega-events beyond their economic outcomes is frowned upon given that they have little trickle down effects on local communities, with recent mega-events focusing on 'greening' rather than being the most socially inclusive (Minnaert, 2012).

\section{Event Sustainability and Environmental Impacts}

Events-related research has grown exponentially over the last 25 years (Getz and Page, 2016) showcasing the increasing importance of events in our society. In a review of 85 event impact studies, Sherwood (2007) noted that only two studies explicitly assessed the environmental impacts of events. In a more recent review by Mair and Withford (2013), these authors suggested that research in this area has dealt mainly with three topics: event impacts, the link between events and tourism, and event types and definitions. One major conclusion of their study was that socio-cultural and environmental impacts of events are under-researched. Economic impacts of events have been prioritized (e.g. Case et al., 2010; Getz, 2008; Mariani and Zan, 2011) but such studies have been criticized for their validity and practical use (Getz, 2009), often neglecting the socio-cultural and environmental outcomes of events (Davies et al., 2013).

Nonetheless, scholars have crafted and introduced reasonable measures and indicators of intangible impacts (Carlsen et al., 2001) and advanced a triple bottom line approach to event sustainability (Dolles and Söderman, 2010; Sherwood, 2007). Concepts such as the 'event footprint' (Fredline et al., 2005), 'event greening' (Mair and Jago, 2010), and the 'event legacy planning' 
(Thomson et al., 2013) have emerged in the tourism and events literature. Research on these concepts has been growing (Case, 2013; Goldblatt and Goldblatt, 2012; Mair and Jago, 2010; Pernecky and Luck, 2012). For example, Mair and Jago (2010) define event greening as an investment in environmental friendly facilities and practices. Alongside, measures to evaluate environmental sustainability have been developed (Collins et al. 2009, 2012) such as the ecological footprint of events that assesses, for example, consumption and waste (Andersson et al. 2012; Andersson and Lundberg, 2013).

\section{Environmental Certification}

The increasing concern for the environmental impacts of business activities has contributed to the development of a number of standards over the years to guide organizations in the adoption of Environmental Management Systems (EMS) (Trierweiller et al., 2013). Currently, the most widespread voluntary standards are the Eco-Management and Audit Scheme (EMAS) created in 1993 by the European Commission and the ISO 14001 developed in 1996 by the International Organization for Standardization (ISO). Both imply that a company voluntarily implements a structured management system consisting of a number of stages that define organizational policies, procedures and practices related to environmental issues (Hillary, 2004), leading eventually to an environmental certification (Black and Crabtree, 2007). The motivation for organizations to meet environmental standards can be twofold: (i) to positively react to demand and pressures from different stakeholders concerned with ecological issues (Demirel and Kesidou, 2011; Xuan-Quynh et al., 2014); and (ii) to obtain a competitive advantage as a result of implementing EMS (Blanco et al., 2009; Mariani, Czakon et al., 2016; Nishitani et al., 2012).

Interestingly, environmental certification has somehow a longer tradition in the travel and tourism industry with the launch of the Blue Flag Campaign for beaches by the Foundation for Environmental Education in Europe (FEEE) in 1987. Almost one year later, the "Silberdistel" label for lodging and restaurants was initiated in Kleinwalsertal (Austria). According to an ECOTRANS 
study (Hamele and Eckhardt, 2006), more than 60 environmental tourism certification programs have been developed between the Earth Summit in 1992 and the International Year of Ecotourism in 2002. Most of these were voluntary and based in Europe, with a few taking socio-cultural factors into account (Bien, 2006). Harmonized standards were developed after 2000 in Europe (e.g., VISIT standard) and America (e.g., Sustainable Tourism Certification Network of the Americas). Other certification schemes (see Honey, 2003) have been developed and embraced by destinations (e.g., the Costa Rica's Certificate for Sustainable Tourism (CST) or the Australia's Nature and Ecotourism Accreditation Program (NEAP) certification scheme). More recently, in July 2008, the US Environmental Protection Agency (USEPA) and the Green Meeting Industry Council (GMIC) agreed to work with the Convention Industry Council's Accepted Practices Exchange (APEX) and the American Society for Testing and Materials International (ASTM International) to develop a uniform measurement of environmental performance, and to define what is "green" according to the meetings and events industry.

Existing research on certification processes and schemes has addressed impacts, decisionmaking and perceptions. Among studies dealing with impacts, beach certification schemes (BCSs) have been found to be ineffective as tools for achieving a high level of sustainability (Zielinski and Botero, 2015) but niche markets exist which are influenced by eco-labelling when choosing among alternative tourist providers (Karlsson and Dolnicar, 2015). Studies on decision-making processes have found that tourism companies and services tend to undergo certification mostly to avoid legal challenges. For instance, Bonilla-Priego et al. (2011) analyzed the pro-environmental behavior of Spanish EMAS certified hotels and found that most hotels were internally driven in their purpose and ad hoc in their decision-making, with limited understanding of externally driven benefits and motivation for more systematic management systems.

Research on perceptions of tourism certifications by visitors and residents is recent. For example, Esparon et al. (2014) surveyed visitors to the Wet Tropics World Heritage Area in Queensland, Australia about the perceived importance and performance of operators on various 
attributes of the ECO certification scheme. Their results confirm that perceptions of attributes varied across product and visitor groups. These authors emphasized that the success of certification schemes depends on consumers' confidence in the quality of products and services that the schemes endorse.

Certification programmes for tourism businesses have a longer tradition (e.g., the Green Tourism Business Scheme is the World's Leading Sustainable Tourism Programme) than standards, certifications and practices for green events. Events have started environmental certification with the ISO2012:2, a British Standard developed specifically for the events industry and certified for the first time by the Swiss Société Générale de Surveillance on the occasion of the London Olympic Games. Research on the adoption and consequences of ecological standards and environmental certification is virtually absent from the extant literature (Getz and Page, 2016). Given that the Milan World Expo 2015 is the first Universal Exposition with a CES provides an opportunity to study perceptions of residents for both the certification and environmental impacts of the event.

\section{Perceptions of Environmental Impacts and Residents' Overall Attitude}

Undeniably, events are not relevant only to visitors but also for residents who are often in a better position than visitors to provide accurate and realistic assessments of environmental impacts. Chen and Tian (2015) suggest that existing studies on perceptions of events can be divided into two major categories. The first category measures the perceptions of event (e.g., Cheng and Jarvis, 2010) or mega-event impacts by residents (e.g., Gibson et al., 2014; Gursoy et al., 2011; Lee et al., 2013; Lorde et al., 2011). The second category focuses on the perceptions as well as the attitudes of residents toward events/mega-events simultaneously (Gursoy and Kendall, 2006; Kaplanidou et al., 2013; Kim and Petrick, 2005; Prayag et al., 2013; Zhou and Ap, 2009; Xiang et al., 2015). However, the terms 'attitude' and 'support' have been used interchangeably in the literature (Ko and Stewart, 2002; Zhou and Ap, 2009), casting doubt on their psychometric properties in events research. Prayag et al. (2013) 
clearly showed that overall attitude and support are distinct constructs in the context of the 2012 London Olympic Games.

The theoretical frameworks that have been used to understand perceptions of mega-events by residents and tourists are diverse. For example, Social Exchange Theory (SET) has been used to explain the perceptions and attitudes of residents according to their experiential and psychological outcomes. For instance, Gursoy and Kendall (2006) found that backing for mega events by residents is affected directly and/or indirectly by five determinants of support: the level of community concern, eco-centric values, community attachment, perceived benefits, and perceived costs. Prayag et al.'s (2013) study of the London Olympics suggest that perceived economic and socio-cultural impacts (positive and negative) influence overall attitude (which in its turn impacts support) while perceived environmental impacts do not. Social Representations Theory (SRT) has been used to examine the opinions shared by groups of people (Fredline and Faulkner, 2000). According to this theory, residents' attitudes towards events can be affected by their direct experiences, personal and societal values, social interaction, and other sources of information such as the media.

SET and SRT are distinctly operative in different contexts but can complement each other in explaining perception changes by residents (Xiang et al., 2015). For example, Xiang et al. (2015) track the evolving attitudes of local residents toward the 2010 Shanghai Expo over the full life cycle of the mega-event. Their findings show that most residents held similar perceptions at the beginning of and six months after the Expo had concluded. However, residents' perceptions at the Expo's conclusion were mostly negative. Irrespective of the theory used, residents have better attitudes and support for an event when the benefits and interests gained outweigh the costs (Chen and Tian, 2015). Also, scholars investigating residents' attitudes or support for events (e.g., Kwon and Vogt, 2010; Zhou and Ap, 2009) suggest that positive attitudes lead to stronger support for the event. Prayag et al. (2013) suggest that overall attitude mediates the relationship between perceived impacts and support. Using the theory of reasoned action (TRA), these authors argued that a person's behavior is a function of his/her attitudes (Fishbein and Ajzen, 1975). Hence, residents' perceptions of event 
impacts can influence their overall attitudes toward the event, in turn influencing their support of the event (Prayag et al., 2013).

Surprisingly, despite increasing environmental concerns by stakeholders for hosting a mega event, not a single study has examined the role and influence of certifications on residents' perceptions of both the positive and negative environmental impacts. Also, no analysis has been conducted on the relationship between perceptions of environmental certification for an event and overall attitude towards the event. In order to bridge these gaps in the literature, the study sets out to investigate residents' perceptions of the environmental impacts and certification for the Milan World Expo 2015 and their overall attitude towards the event.

\section{Methods}

The EXPO 2015 and its Environmental Commitments

The city of Milan hosted the Universal Exposition from the $1^{\text {st }}$ of May 2015 to $31^{\text {st }}$ of October 2015. It was estimated that the Italian public sector had invested Euros 474 million on the Expo just for the facilities (Gallione, 2015). The Waterways Project, which was part of the sustainability theme for the Expo was explicitly included in the Expo bid, with a commitment to develop the venues for the Expo and where possible, ensuring the utilization of all built facilities after the event. The Expo 2015 was also committed to comply with the international standard ISO 20121 for its management system for event sustainability.

The environmental commitments made by the Expo 2015 can be grouped into three main categories based on the sustainability reports issued in 2013 and 2014 (Expo Company, 2013, 2014). The first category consists of six broad macro environmental objectives such as minimization of energy demand, use of energy from renewable sources, use of products and services with lower environmental impacts, reduction in the production of waste at source as much as possible, reduction 
in water consumption and the adoption of water recycling systems, and assessments of the environmental impacts of activities carried out. The second category relates to the application of environmental and sustainability standards recognized at international levels such as the European Regulation EMAS 1221/2009/EC and ISO 14001:2004 on environmental management system, ISO 20121: 2012 on event sustainability management system, and ISO 14064:2006 on greenhouse gases (GHG or $\mathrm{CO} 2$ equivalent gas emissions). This category of commitments also includes the LEED (Leadership in Energy and Environmental Design) protocol by the U.S. Green Building Council (USGBC) to evaluate sustainable building as well as the sustainability reporting guidelines of the Global Reporting Initiative (GRI). The last category, measuring and reporting on the performance achieved annually, includes monitoring of various environmental receptors impacted by the event, creation of the Inventory of $\mathrm{CO} 2$ equivalent gas emissions (CO2eq), and preparation/dissemination of the sustainability reports.

\section{Questionnaire Development}

The questionnaire developed for this study consisted of several rating scales to capture the study's main variables: perceptions of environmental impacts, awareness of environmental certification, perceptions of environmental certification and overall attitude towards the event. For perceived positive and negative environmental impacts, respondents had to rate their level of agreement/disagreement $[1=$ Strongly Disagree and $5=$ Strongly Agree $]$ with eleven items adapted from the literature (Gursoy et al., 2014; Lorde et al., 2011; Ritchie et al., 2009). A five-point scale is commonly used in tourism impact studies on residents (see Gursoy et al., 2014). The awareness of environmental certification was measured using a binary variable (Yes/No): "Do you know that the Expo 2015 is endowed with a certification for Event Sustainability?" Perception of environmental certification was operationalized using one statement: "The certification for event sustainability will limit the damage to the natural environment", measured on five-point likert scale anchored on 1=Strongly Disagree and 5=Strongly Agree. Given that there is no study that measures residents' 
perceptions of an event certification, this statement was purposefully developed for this study based on practitioners and business reports (UN Environment Programme, 2012) to capture an overall perception of what should be the main purpose of an environmental certification.

Attitude towards the Expo was operationalized as summative overall measures. Two statements (Prayag et al., 2013; Vargas-Sanchez et al., 2011) capture residents' overall attitude: “I am excited about Milan hosting the 2015 World Expo"; and "Overall, the Expo positive impacts will outweigh its negative ones". In addition, the research instrument included standard sociodemographic background questions (such as age, gender, length of residence in Milan, and educational level). The original version of the questionnaire was developed in English but administered in Italian. The backtranslation technique was used to ensure cross-cultural equivalence of the questionnaire.

\section{Sampling and Data Collection}

The population of interest was defined as residents of Milan. In the absence of an adequate sampling frame and consistent with previous research (e.g., Gursoy and Kendall, 2006; Lorde et al., 2011), a convenience sampling method was used to select participants. Residents were informed about the study's purpose and two screening questions were asked to identify the target population: 1) Are you a resident of Milan? 2) Do you know that the World Expo 2015 will take place in Milan? Data were collected prior to the event over a one month period in March 2015 ( $1^{\text {st }}$ to $31^{\text {st }}$ of March). In the events literature, pre-event impact assessments remain the most common research design (e.g., Ritchie et al., 2009; Zhou and Ap, 2009). To minimize selection bias, one of the researchers administered the questionnaire at several locations including three major Milan parks, a few subways/bus stops, bars and shops on different days and times of the week, including weekends. The selected locations for questionnaire administration represent the nine neighborhoods of Milan so that a diverse sample in terms of socio-demographics could be captured. Of the 489 residents approached, a total of 221 (response rate of 45.2\%) completed the questionnaire. 


\section{Data Analysis and Model}

When working with bounded and ordinal dependent variables, attaching a number to the response categories, e.g., 1, 2,..,J simplifies the use of conventional linear regression and ANOVA models. However, this approach is over-confident to a certain extent given that the choice of the scoring imposes assumptions about the distance between the response categories. As such, the data are assumed to contain more information than they actually do (Christensen, 2015). The use of linear regression should be carefully evaluated when the categorical response presents "naturally" nonconstant variability (heteroskedasticity) given that the measurement scale cannot be thought of as the discretization of a continuous normal variable. Non-normality and heteroscedasticity can cause the standard errors of the linear regression parameters to be estimated incorrectly by the Ordinary LeastSquare (OLS) method. Accordingly, any test for parameters significance is biased and confidence intervals may lead to wrong conclusions about causal relationships among the variables. Linearity assumption can also yield predicted values above the highest or below the lowest category score.

All the aforementioned issues are less relevant when the sample size is large enough (i.e "tends to infinity"), and/or the dependent variable is distributed almost symmetrically. When these conditions do not hold, literature suggests that linear regression should be avoided in favor of a Cumulative (ordered) Logit Model (CLM) (Christensen, 2015; Winship and Mare, 1984). In fact, this approach is specifically designed to assess the intensity and significance of causal relationships among bounded and ordinal scale variables without requiring error (and dependent variable) normality or homoscedasticity (Agresti, 2010).

In our empirical setting, the three variables in the study (perception of environmental certification and the two items of resident overall attitude toward the Expo) were negatively skewed. For this reason, instead of the usual linear regression model, we used the following CLM with parallel assumption: 


$$
\begin{gathered}
Y=\alpha+\beta^{\prime} X+\varepsilon \\
y_{i, j}=\ln \left(\frac{P\left[S_{i}>J\right]}{1-P\left[S_{i}>J\right]}\right)=\ln \left(\frac{1-\sum_{k=1}^{j} P\left[S_{i}=k\right]}{\sum_{k=1}^{J} P\left[S_{i}=k\right]}\right)
\end{gathered}
$$

where $S_{i}$ is the agreement scale, expressed by the $\mathrm{i}^{\text {th }}$ respondent; $\mathrm{J}=1,2, . ., 5$ the range of the agreement scale and $\varepsilon_{k}$ is the vector of error terms. For direct interpretation of $\beta^{\prime}$ parameters, we consider an inverse cumulative logit parametrization, where the event being modelled has an outcome in a higher category. Each outcome (except one) has its own $\alpha$ intercept, a vector of $(J-1)$ thresholds to be estimated but the same regression coefficients $\beta^{\prime}$ for the independent variable $\mathrm{X}$. This means that the baseline (average) inverse log odd of any event $\left(y_{i, j}\right.$; with $\left.j=1,2, . ., 5\right)$ can differ, as it is shifted by the corresponding $\alpha_{j}$ threshold, but the effect of the predictors on $y_{i, j}$ is the same for every category $J$. In geometric terms, the proposed CLM describes $\mathbf{J}$ parallel regression line where the estimated thresholds $\alpha_{j}$ are the intercept and the estimated beta is a (common) slope.

The most natural way to interpret ordered response models (and discrete probability models in general) is to determine how a marginal change in one regressor changes the distribution of the outcome variable, i.e. all the outcome probabilities. The estimated beta coefficients quantify the changes in $y_{i, j}$ produced by a unitary variation in the correspondent regressor, i.e. how much lower/higher is the probability that the agreement scale, expressed by the i-th respondent $S_{i,}$, would be higher than the observed outcome J, ceteris paribus. For example if we consider as dependent variable the excitement about Milan hosting the expo 2015, a positive beta implies that a unitary increase in the value of the corresponding independent variable will increase also the probability that residents will be more excited about Milan hosting the expo 2015, than they are with the observed value of that variable. In other words, if Xs are continuous, the beta coefficient in the CLM can be 
interpreted in a similar way to a beta coefficient in a "simple" linear regression: each variable has its own coefficient affecting $y_{i, j}$. Also in the case of ordinal Xs, the CLM returns (J-1) coefficients for each independent variable as it happens in a linear regression when an ordinal dependent variable is categorized into J-1 dummy variables.

\section{Findings}

Demographic Profile

A summary of the demographic profile of respondents is shown in Table 1. The survey polled an almost equal number of males (49.8\%) and females (50.2\%). Approximately $28 \%$ of the sample was aged between 26 and 35 years old and slightly more than 39\% had completed high school. More than $44 \%$ of the sample had an average household income of between Euros 15,001 and 28,000, with more than half $(56.1 \%)$ residing in Milan for more than 12 years. The occupation of respondents was diverse, with $16.3 \%$ and $18.6 \%$ describing themselves as self-employed and student respectively.

[Insert Table 1 about here]

\section{Dimensions of Environmental Impacts}

Residents, on average, disagreed with seven of the eleven environmental impacts measured (see Table 2). In general, residents disagreed with the Expo having negative environmental impacts such as damage to the natural environment $(\mathrm{M}=2.56, \mathrm{~S} . \mathrm{D}=1.24)$, and increasing noise $(\mathrm{M}=2.26$, $\mathrm{S} . \mathrm{D}=1.16)$, air $(\mathrm{M}=2.71, \mathrm{~S} . \mathrm{D}=1.00)$ and visual $(\mathrm{M}=2.75, \mathrm{~S} . \mathrm{D}=1.03)$ pollution. Residents also disagreed with the positive environmental impacts of the Expo on conservation of natural resources $(\mathrm{M}=2.33$, S.D=1.25), raising of environmental awareness $(M=2.38, S . D=1.24)$ and improving environmental protectionism (M=2.29, S.D=1.13). Overall, the results tend to suggest that residents perceived that the Expo will have minimal negative and positive environmental impacts. 
The results of the adequacy of the sample size and suitability of the data for factorization, using KMO measure of sampling adequacy (0.71) and Bartlett's test of sphericity $\left(\chi^{2}=855.84\right.$, $\mathrm{p}<0.001)$ respectively, confirmed factor analysis as an appropriate analytical tool to identify underlying dimensions in the data. Using a varimax rotation, three underlying dimensions of environmental impacts were extracted explaining $63.4 \%$ of total variance. Of these dimensions, factor one was related to negative environmental impacts while factors two and three were related to positive environmental impacts of the event. The factors were labelled 'Negative Environmental Impacts', $(\mathrm{M}=2.84, \mathrm{~S} . \mathrm{D}=0.76)$ 'Positive Environmental Impacts' $(\mathrm{M}=2.33, \mathrm{~S} . \mathrm{D}=1.06)$ and 'Positive Impacts on City Infrastructure' $(M=3.25, S . D=0.87)$ respectively. The Cronbach's alpha values $(\alpha>0.6)$ were acceptable (Hair et al., 2005), which confirmed the reliability of this factor solution (see Table 2).

[Insert Table 2 about here]

\section{Awareness of Environmental Certification and Environmental Impacts}

Only $8.1 \%$ of residents were aware of the environmental certification of the event. A t-test revealed no significant differences between those residents that were aware of the environmental certification and those that were not on their agreement levels with the three environmental impact factors identified previously. However, awareness of environmental certification had a significant relationship with length of residence in Milan $\left(\chi^{2}=12.09, \mathrm{p}<0.05\right)$. Residents were more aware of the certification if they had stayed between 10 and 12 years $(27.8 \%)$ and more than 12 years $(22.2 \%)$ than if they had stayed for a shorter time $(1-3$ years $=16.7 \%$ and $4-6$ years $=11.1 \%)$. Interestingly, when asked about whether the certification of event sustainability for the World Expo should limit the damage to the natural environment, residents on average were neither agreeable nor disagreeable $(\mathrm{M}=3.12$, S.D=0.97). This statement was used as the dependent variable in an ordinal logistic regression model (see eq. 1) where the three independent variables were specified as the three identified environmental impact factors. 
Diagnostics indicated that the final model gives a significant improvement over the baseline intercept-only model $\left(\chi^{2}=58.7, \mathrm{p}<0.001\right)$, that is, the model gives better predictions than models based on the marginal probabilities for the outcome categories. The goodness-of-fit statistic indicates a pseudo $\mathrm{R}^{2}$ of $25 \%($ Nagelkerke $=0.25)$. The Deviance chi-square test $\left(\chi^{2}=483, \mathrm{p}>0.99\right)$ indicates a good fit, while Pearson's chi-square statistic would suggest to reject the null hypothesis that the fit is good $\left(\chi^{2}=912, \mathrm{p}<0.001\right)$. The Pearson's chi-square statistic could be conditioned by the fact that continuous covariates are used in the model and thus Pearson's statistic is inflated by low expected frequencies. Accordingly, the deviance was used to assess goodness-of-fit rather than Pearson's (Field, 2013).

Consistently with the model definition, the alpha coefficient estimates (see table 3) reflect the expected probability to observe an agreement higher than $\mathrm{J}$ - net of the effect of the $\mathrm{X}$ 's. As an example the threshold coefficient $\alpha_{2}=0.67$ (for $\mathrm{J}=2$ ), indicates that the expected probability of an agreement level higher than 2 about the certification of event sustainability limiting the damage to the natural environment, is equal to $66 \%$, as $\left(\frac{\exp \left(\alpha_{2}\right)}{1+\exp \left(\alpha_{2}\right)}\right)=66 \%$. However, similar to a linear regression, the most interesting coefficients are the betas. They show that the factor 'Negative Environmental Impacts' has a significant, negative relationship with the dependent variable suggesting that the frequency of residents agreeing that environmental certification should limit the damage to the natural environment is higher among residents expressing lower levels of agreement with the event having negative environmental impacts. Likewise, the factor 'Positive Impacts on City Infrastructure' shows a positive significant beta coefficient, suggesting that if residents' perceptions of positive environmental impact increase, the probability that residents will agree that the certification of event sustainability should limit the damage to the natural environment also increases.

[Insert Table 3 about here] 
In general residents had somewhat positive overall attitudes towards the event given that the two items 'Overall, the Expo positive impacts will outweigh its negative ones' $(M=3.82, S . D=1.01)$ and 'I am excited about Milan hosting the 2015 World Expo' $(M=4.03, S . D=1.04)$ were on average rated above the mid-point of the scale.

Two ordinal logistic regression models (see eq. 1) were estimated to predict overall attitudes based on the three environmental impact factors identified earlier and the item for perception of certification for event sustainability

Considering the item 'Overall, the Expo positive impacts will outweigh its negative ones' as the dependent variable, the final model (see table 4) gives a significant improvement over the baseline intercept-only model $\left(\chi^{2}=114.4, \mathrm{p}<0.001\right)$. The goodness-of-fit statistic indicates a pseudo $\mathrm{R}^{2}$ of 43.4\% (Nagelkerke=0.434). The Pearson's goodness-of-fit statistics was significant $\left(\chi^{2}=2799.7\right.$, $\mathrm{p}<0.001)$ while the Deviance test $\left(\chi^{2}=449, \mathrm{p}>0.99\right)$ was not significant. As previously discussed, the deviance was used to assess goodness-of-fit. All the estimated coefficients were significant and higher agreement levels with the Expo positive impacts outweighing the negative impacts were associated with low values of the factor 'Negative Environmental Impacts'. The factor 'Positive Environmental Impacts' showed a positive relationship with the dependent variable. Also, the factor 'Positive Impacts on City Infrastructure' had a significant positive relationship with the dependent variable. The frequency of residents strongly agreeing that the expo will have positive impacts that will outweigh negative ones is lower among residents who strongly disagreed that the event will have positive impacts on the city's infrastructure. Finally, the item for perception of certification for event sustainability is a significant predictor of overall attitude. The estimated coefficients were higher for overall attitude in correspondence with higher agreement levels that the certification of event sustainability should limit the damage to the natural environment. For example, higher agreement levels with the latter are associated with higher agreement levels that the Expo's positive impacts will outweigh its negative ones.

[Insert Table 4 about here] 
Considering the item "I am excited about Milan hosting the 2015 World Expo" as the dependent variable (table 4) the results indicated that the model gives a significant improvement over the baseline intercept-only model $\left(\chi^{2}=132.9, \mathrm{p}<0.001\right)$. The results indicated that the three factors of environmental impacts and the item for certification of event sustainability were useful predictors of the dependent variable (Nagelkerke pseudo $\mathrm{R}^{2}$ is $48.8 \%$ ). In this model, both Pearson's and Deviance goodness of fit statistics were not significant, indicative of a good fit (Pearson's $\chi^{2}=662.67, p>0.997$ ). All the estimated coefficients are significant and with the expected sign. The frequency of residents agreeing that they were excited about Milan hosting the world expo was lower if they agreed that the event would have negative environmental impacts. Residents' excitement levels about Milan hosting the world Expo are higher if they agree that the event will have positive environmental impacts and positive impacts on the city's infrastructure. Also, the item for certification of event sustainability was a useful predictor and had a positive relationship with the dependent variable. The frequency of residents disagreeing that they were excited about Milan hosting the world Expo was higher if they disagreed that a certification for event sustainability will limit the damage on the natural environment.

Overall, the results of the two ordinal inverse logit regression models suggest that the more residents perceived that a certification for event sustainability will limit the damage on the natural environment, the more they perceived the overall positive impacts of the event outweighing negative impacts and the more excited they were about the Expo. Additionally, the frequency of residents having positive overall attitudes, as evidenced by the two aforementioned indicators, was higher if they agreed that the Expo will have positive environmental impacts and positive impacts on the city's infrastructure. Lower frequencies of residents having positive overall attitudes, as evidenced by the two aforementioned indicators, occurred if they agreed that the event will have negative environmental impacts. The Expo's environmental impacts are thus central to explaining residents' overall attitude towards the event. However, residents also perceived the Expo as having minimal 
negative and positive environmental impacts, a limitation to the positive role played by the certification.

\section{Discussion and Conclusions}

\section{Conclusions}

The main objective of the study was to examine perceptions of environmental impacts and a CES for the Milan World Expo 2015 by residents and their overall attitude towards the event. The findings indicate that residents perceived the event will have minimal negative and positive environmental impacts. A minority of residents were aware of the environmental certification of the event. The less agreeable residents were with the perceived negative environmental impacts of the event, the more agreeable they were that a certification of event sustainability should limit the damage to the natural environment. Residents' perceptions of the certification were positively associated with their overall attitude towards the event. By far the findings suggest that residents are possibly more concerned about the economic and social impacts rather than environmental impacts before a megaevent event as suggested in previous studies (Ap, 1992; Kim et al., 2015; Zhou and Ap, 2009). Also, awareness and knowledge of a CES is generally lacking in the hosting community of Milan. For policy makers, destination and event managers, the findings highlight the need for stakeholders to play a more active role in educating residents about the importance of a CES. As such, the study contributes to the limited literature on the relationship between environmental certification and perceptions of environmental impacts, and has several theoretical and managerial implications.

\section{Theoretical Implications}

In terms of the theoretical implications, given that residents neither perceived the event to have strong negative nor positive environmental impacts may suggest that SET is not effective at capturing residents' evaluations of environmental impacts. Several plausible explanations can be offered for this occurrence. First, residents are possibly more concerned about the economic and 
social impacts rather than environmental impacts before the event. This has been shown in previous tourism and event studies using SET (Ap, 1992; Zhou and Ap, 2009) whereby the host population is more concerned about the positive economic benefits rather than the negative environmental impacts or social costs.

Second, the type of mega-event analyzed (a World Exposition) differs significantly from the sports mega-events typically analyzed in tourism and events literature such as the Winter Olympic Games (Gursoy and Kendall, 2006), the Summer Olympic Games ( Lee et al., 2013; Prayag et al., 2013; Zhou and Ap, 2009), and the FIFA World Cup (Kim and Petrick, 2005). Accordingly, there are differences in the way residents evaluate the impacts of such different types of event. This seems to be consistent with the tourism literature suggesting that tourism impacts are not universal and dependent on the type and nature of the tourism development (Tosun, 2002; Zhou and Ap, 2009).

Third, the Expo 2015 is an event branded around the concept of sustainability due to its theme of "Feeding the Planet, Energy for Life". However, residents paradoxically perceive low positive environmental impacts of the event. This may imply that either residents are not aware of the Expo's branding proposition or simply that a communication gap on issues of environmental sustainability of the event exists between the organizers and residents (e.g., there is limited information on the Expo's website about sustainability issues and the sustainability reports in themselves are not easy to find). Rather surprisingly, when asked about whether the certification of event sustainability for the Expo should limit the damage to the natural environment, residents were neither agreeable nor disagreeable. This may indicate that residents are not informed about the existence of an environmental certification or about its role in attenuating negative environmental impacts. This lack of information and communication may negatively impact residents' perceptions of the event and may have detrimental outcomes for the overall city branding (Marin-Aguilar and Vila-López, 2014). The fact that very few residents are aware of the CES and this group consists of mainly residents, who have lived in Milan for a long time, reinforces the argument that communication activities 
surrounding the environmental outcomes of the event for the community have been largely ineffective.

Fourth, in this study perceptions of environmental impacts were measured prior to the event. Accordingly, it is likely that residents were not fully exposed to the environmental consequences of the event and that "event-related euphoria" was absent (Gibson et al. 2014). Yet, the results confirm that perceived positive and negative environmental impacts influence overall attitudes of residents as suggested in previous tourism studies (Ko and Stewart, 2002). This finding contradicts previous studies that show no significant relationship exists between perceived positive/negative environmental impacts and overall attitudes prior to the event (see Prayag et al., 2013). Hence, event organizers should communicate to residents the positive environmental impacts of the event to improve overall attitudes and encourage supportive behaviors during the event.

\section{Practical Implications}

In terms of managerial implications and policy making, the findings of the study suggest that the communication activities surrounding event environmental certification by the organizers have been largely ineffective for Milan Expo 2015. Residents are neither aware of the CES nor perceive the event to contribute positively to the community. Mega-event organizers and planners should have a clear communication strategy prior to an event to inform residents not only about the economic benefits but also about the environmental and social benefits of an event. Given that environmental certification of events is a new phenomenon, it may be worthwhile for event organizers and policy makers to educate both residents and event attendees about the relevance and importance of such certification for managing event impacts on the host community. This highlights the need for megaevent organizers and local government to develop educational initiatives that familiarize the host community with a CES before the event. Relatedly, it is necessary that managers of the event coordinate the marketing and branding strategies (Mariani, 2015; Mariani and Giorgio, 2017) in a 
manner that emphasize the theme of the world expo (i.e. sustainability) as well as its positive environmental impacts to boost event awareness and support.

For policy makers at the local and national level in Italy and beyond, the findings suggest that residents were possibly in a state of apathy given that they neither perceived high positive nor high negative environmental impacts of the event, similar to previous studies on residents' perceptions of mega-events (Prayag et al., 2013). Accordingly, event organizers and local government need to raise public awareness about the event and its impact on the city. Moreover, destination marketing and branding strategies for a city destination should not be developed in isolation of the events being hosted. Incorporating event certification as part of the destination integrated marketing communications (IMCs) (Morrison, 2013) would create wider awareness, increased importance, and potentially improved perceived impacts of a mega event among various stakeholders due to the certification. At the time of writing, information about the CES does not feature prominently on the webpage of the Milan Expo. This is a missed opportunity for event organizers to use the website as well as social media to create awareness and interest in environmental sustainability of events as well as the environmental commitments of the event through the certification. This may be an outcome of different stakeholders having different perspectives on the event which is not uncommon. Accordingly, the deployment of techniques as the Q method (Phi et al., 2014) might be helpful in an attempt to reconcile different perspectives on the event by stakeholders. Specifically, this method may be useful at the event planning stage and when seeking accreditation for a CES.

From a marketing point of view, there is also a missed opportunity in terms of event promotion for residents and industry stakeholders. Given that Expo 2015 is the first event to be endowed with a CES, event organizers should be promoting this achievement at major travel shows and exhibitions in Europe (ITB in Germany, World Travel Market in the UK, MITT in Moscow, TTG and BIT in Italy). Moreover, in a world were both physical and digital networks are becoming increasingly important (Mariani et al., 2014), social media such as Facebook or Twitter might have been used more pronouncedly to promote not only the event and the destination (Mariani, Di Felice and Mura, 
2016; Mariani, Di Felice and Mura, 2017) but also to increase the buzz about CES. The more stakeholders are aware of and embrace CES, the better informed potential hosts for mega events will be to understand environmental sustainability as well as how to use the certification as a major selling and communicating point for the event. Given that CES is still in its infancy, awareness and support for its implementation as part of event hosting will be necessary to manage the both positive and negative impacts of mega events on host communities.

\section{Limitations and Future Research}

Despite attempting to clarify the role and influence of a certification of event sustainability on residents' perceptions of environmental impacts and overall attitude towards the event, the study is not without limitations. First, while we believe that the World Expo 2015 is an exemplar case to test the role of certification for events sustainability, our findings cannot be generalized to all residents of Milan and event attendees and should be interpreted with caution. To this aim, future studies should try to compare perceptions of environmental impacts both before and after the event on a larger sample of residents. Second, awareness of the environmental certification for the event was low among residents and measured using a binary variable. Residents might have been relying on previous knowledge to assess what generally an environmental certification can do and this may have introduced a recall bias in the findings. Future studies can investigate awareness of a certification in more depth using multiple items and dimensions. Third, perceptions of environmental certification were measured using only one global evaluation item. Environmental certifications generally limit not only damage to the natural environment but also consumption of resources such as energy. It would be worthwhile for future studies to evaluate perceptions of the environmental certification using multiple items that depict various dimensions of such certifications. Finally, but importantly, a longitudinal approach in understanding how perceptions of environmental impacts as well as economic and social impacts change over different phases of an event life cycle may be necessary to understand the relationship between residents' perceptions and overall attitude towards an event. 


\section{References}

Agresti A. (2010), Analysis of ordinal categorical data, Wiley, Hoboken, NJ.

Andersson, T., Armbrecht, J., and Lundberg, E. (2012), "Estimating use and non-use values of a music festival", Scandinavian Journal of Hospitality and Tourism, Vol. 12 No 3, pp. 215-231.

Andersson, T. D. and Lundberg, E. (2013), “Commensurability and sustainability: triple impact assessments of a tourism event", Tourism Management, Vol. 37, pp. 99-109.

Ap, J. (1992), “Residents’ perceptions on tourism impacts“, Annals of Tourism Research, Vol. 19 No. 4, pp. 665-690.

Bien, A. (2006), “A Simple user's guide to certification for sustainable tourism and ecotourism”, Center on Ecotourism and Sustainable Development (CESD), Washington DC.

Black, R. and Crabtree, A. (2007), Quality Assurance and Certification in Ecotourism. CABI Press, Wallingford, England.

Blanco, E., Rey-Maquieira, J. and Lozano, J. (2009), "Economic incentives for tourism firms to undertake voluntary environmental management", Tourism Management, Vol. 30 No. 1, pp. 112-122.

Bonilla Priego, M.J., Najera, J.J., and Font, X. (2011), "Environmental management decision-making in certified hotels", Journal of Sustainable Tourism, Vol 19 No 3,pp. 361-381.

Bramwell, B. (1997), “A sport mega-event as a sustainable tourism development strategy,” Tourism Recreation Research, Vol. 22 No. 2, pp. 13-19.

Callicott, J. B., and Mumford, K. (1997), "Ecological sustainability as a conservation concept," Conservation Biology, Vol. 11 No. 1, pp. 32-40.

Carlsen, J., Getz, D., and Soutar, G. (2001), “Event evaluation research”, Event Management, Vol. 6 No. 4 , pp. $247-257$.

Case, R. (2013), Events and the environment, Routledge, London.

Case, R., Dey, T., Hobbs, S., Hoolachan, J., and Wilcox, A. (2010), “An examination of sporting event direct-spending patterns at three competitive levels", Journal of Convention \& Event Tourism, Vol. 11 No 2, pp. 119-137.

Chen, F and Tian, L. (2015), "Comparative study on residents' perceptions of follow-up impacts of the 2008 Olympics", Tourism Management, Vol. 51, pp. 263-281.

Cheng, E. and Jarvis, N. (2010), "Residents' perception of the social-cultural impacts of the 2008 Formula 1 Singtel Singapore Grand Prix", Event Management, Vol. 14 No. 2, pp. 91-106.

Christensen R.H.B., (2015), Analysis of ordinal data with cumulative link models - estimation with the R-package 'ordinal', Available at https://cran.r-project.org/web/packages/ordinal/vignettes/clm_intro.pdf, (accessed 3 January 2016)

Collins, A., Jones, C., and Munday, M. (2009), "Assessing the environmental impacts of mega sporting events: two options?", Tourism Management, Vol. 30 No. 6, pp. 828-837.

Collins, A., Munday, M., and Roberts, A. (2012), "Environmental consequences of tourism consumption at major events: an analysis of the UK stages of the 2007 Tour de France“, Journal of Travel Research, Vol. 51 No.5, pp. 577-590. 
Davies, L., Coleman, R., and Ramchandani, G. (2013), "Evaluating event economic impact: rigour versus reality?", International Journal of Event and Festival Management, Vol. 4 No. 1, pp. 31-42.

Demirel P. and Kesidou, E. (2011), "Stimulating different types of eco-innovation in the UK: Government policies and firm motivations", Ecological Economics, Vol. 70 No. 8, pp. 1546-1557.

Dolles, H. and Söderman, S. (2010), “Addressing ecology and sustainability in mega sporting events: the 2006 football world cup in Germany”, Journal of Management \& Organization, Vol. 16 No. 4, pp. 587-600.

Elkington, J. (1997), Cannibals With Forks: The Triple. Bottom Line of 21st Century Business, Capstone, Oxford.

Esparon, M., Gyuris, E. and Stoeckl, N. (2014), "Does ECO certification deliver benefits? An empirical investigation of visitors' perceptions of the importance of ECO certification's attributes and of operators' performance", Journal of Sustainable Tourism, Vol. 22 No. 1, pp. 148-169.

Expo Company (2014), Second sustainability Report EXPO MILANO 2015, Primaprint S.r.1., Milano.

Expo Company (2013), Sustainability Report EXPO MILANO 2015, Primaprint S.r.l., Milano.

Field, A. (2013), Discovering statistics using IBM SPSS statistics, Sage, London.

Fishbein, M. and Ajzen, I. (1975), Belief, attitude, intention and behavior, Addison-Wesley, Reading, MA.

Fredline, E. and Faulkner, B. (2000), "Host community reactions: a cluster analysis”, Annals of Tourism Research, Vol. 27 No. 3, pp. 763-784.

Fredline, E., Raybould, M., Jago, L., and Deery, M. (2005), “Triple bottom line event evaluation: A proposed framework for holistic event evaluation". Paper presented at the third international event management research conference, Sydney. University of Technology, Sydney.

Gallione, A. (2015), “Appalti Expo, lievitano i costi extra. Cantone: Ancora non sappiamo i prezzi delle opere", $L a$ Repubblica, 2 August 2015, pp. 1-2.

Garrod, B. and Fyall, A. (1998), “Beyond the rhetoric of sustainable tourism?”, Tourism Management, Vol. 19 No. 3 , pp. $199-212$.

Getz, D. and Page, S. (2016), "Progress and prospects for event tourism research", Tourism Management, Vol. 52, pp. 593-631.

Getz, D. (2009), "Policy for sustainable and responsible festivals and events: institutionalization of a new paradigm", Journal of Policy Research in Tourism, Leisure and Events, Vol. 1, No. 1, pp. 61-78.

Getz, D. (2008), “Event tourism: Definition, evolution, and research”, Tourism Management, Vol. 29 No. 3, pp. 403-428.

Gibson, H., Walker, M., Thapa, B., Kaplanidou, K., Geldenhuys, S., and Coetzee, W. (2014), "Psychic income and social capital among host nation residents: a prepost analysis of the 2010 FIFA World Cup in South Africa", Tourism Management, Vol. 44, pp. 113-122.

Goldblatt, S. and Goldblatt, J. (2012), The complete guide to greener meetings and events, Wiley, New York.

Gursoy, D. and Kendall, K. W. (2006), "Hosting mega events: modeling locals' support”, Annals of Tourism Research, Vol. 33 No. 3, pp. 603-623. 
Gursoy, D., Chi, C.G., Ai, J., and Chen, B.T. (2011), “Temporal change in resident perceptions of a mega-event: the Beijing 2008 Olympic Games”, Tourism Geographies, Vol. 13 No. 2, pp. 299-324.

Gursoy, D., Uysal, M., Sirakaya-Turk, E., Ekinci, Y., Baloglu, S. (2014), Handbook of Scales in Tourism and Hospitality Research, CABI Publishing, London.

Hair, J.F., Black, W.C., Babin, B.J., Anderson, R.E., and Tatham, R.L. (2005), Multivariate Data Analysis (6th Ed.), Prentice Hall, New Jersey.

Hall, C. M. (2012), "Sustainable mega-events: Beyond the myth of balanced approaches to mega-event sustainability", Event Management, Vol. 16 No.2, pp.119-131.

Hamele, H. and Eckhartd, S. (2006), Environmental initiatives by European tourism businesses. Instruments, indicators and practical examples., SUTOUR, TourBench, DBU, ECOTRANS: Saarbrücken

Hardy, A., Beeton, R.J. and Pearson, L., (2002), "Sustainable tourism: An overview of the concept and its position in relation to conceptualisations of tourism”, Journal of Sustainable Tourism, Vol. 10 No.6, pp.475-496.

Hillary R. (2004), "Environmental management systems and the smaller enterprise”, Journal of Cleaner Production, Vol. 12 , pp. 561-569.

Holmes, K., Hughes, M., Mair, J., and Carlsen, J. (2015), Events and Sustainability, Routledge: London.

Honey, M. (2003), “Protecting Eden; setting green standards for the tourism Industry”, Environment, Vol. 45 No. 6, pp. $8-21$.

Karlsson, I. and Dolnicar, S. (2015), "Does eco certification sell tourism services? Evidence from a quasi-experimental observation study in Iceland”, Journal of Sustainable Tourism, doi:10.1080/09669582.2015.1088859, pp.1-21.

Kaplanidou, K., Karadakis, K., Gibson, H., Thapa, B., Walker, M., Geldenhuys, S., and Coetzee, W. (2013), “Quality of life, event impacts, and mega-event support among residents before and after the event: the case of the 2010 FIFA World Cup in South Africa”, Journal of Travel Research, Vol. 52 No. 5, pp. 631-645.

Kim, W., Mun Jun, H. Walker, M., and Drane, D. (2015), "Evaluating the perceived social impacts of hosting large-scale sport tourism events: Scale development and validation”, Tourism Management, Vol. 48, pp. 21-32.

Kim, S. S. and Petrick, J. F. (2005), "Residents' perceptions on impacts of the FIFA 2002 World Cup: the case of Seoul as a host city", Tourism Management, Vol. 26 No. 1, pp. 25-38.

Ko, D. W. and Stewart, W. P. (2002), “A structural equation model of residents' attitudes for tourism development”, Tourism Management, Vol. 23 No. 5, pp. 521-530.

Kwon, J. and Vogt, C. A. (2010), "Identifying the role of cognitive, affective, and behavioural components in understanding residents' attitudes toward place marketing”, Journal of Travel Research, Vol. 49 No. 4, pp. 423-435.

Lee, S.-B., Lee, C.-K., Kang, J.-S., Lee, E.-Y., and Jeon, Y.J.J. (2013), "Residents' perception of the 2008 Beijing Olympics: comparison of pre- and post-impacts", International Journal of Tourism Research, Vol. 15 No. 3, pp. 209225.

Lorde, T., Greenidge, D., and Devonish, D. (2011), "Local residents' perceptions of the impacts of the ICC Cricket World Cup 2007 on Barbados: comparisons of pre and post-games”, Tourism Management, Vol. 32 No. 2, 349-356. 
Mair, J. and Jago, L. (2010), "The development of a conceptual model of greening in the business events tourism sector", Journal of Sustainable Tourism, Vol. 18 No.1, pp. 77-94.

Mair, J. and Whitford, M. (2013), "An exploration of events research: event topics, themes and emerging trends", International Journal of Event and Festival Management, Vol. 4 No 1, pp.6 - 30.

Mariani, M.M., Giorgio, L. (2017) “The 'Pink Night' festival revisited: Meta-events and the role of destination partnerships in staging event tourism”, Annals of Tourism Research, Vol. 62 No 1, pp 89-109.

Mariani, M.M., Czakon, W., Buhalis, D., Vitouladiti, O. (2016), "Tourism Management, Marketing, and Development: Performance, Strategies, and Sustainability", Palgrave: New York. http://dx.doi.org/10.1057/9781137401854

Mariani, M.M., Baggio, R., Buhalis, D., Longhi, C. (2014), Tourism Management, Marketing, and Development: Volume I: The importance of networks and ICTs, Palgrave: New York. http://dx.doi.org/10.1057/9781137354358 .

Mariani, M.M, Di Felice, M., Mura, M. (2016), "Facebook as a Destination Marketing Tool: Evidence from Italian regional Destination Management Organizations", Tourism Management, 54, 321-343.

Mariani, M.M, Di Felice, M., Mura, M. (2017), “The determinants of Facebook social engagement for National Tourism Organisations' Facebook pages: A quantitative approach", Journal of Destination Marketing and Management, forthcoming.

Mariani, M.M. (2015), “Coordination in inter-network co-opetitition: Evidence from the tourism sector", Industrial Marketing Management, http://dx.doi.org/10.1016/j.indmarman.2015.11.015

Mariani, M.M., Zan, L. (2011), “The economy of music programs and organizations. A micro analysis and typology”, European Accounting Review, 20(1): 113-148.

Marin-Aguilar, J.T. and Vila-López, N. (2014), "How can mega events and ecological orientation improve city brand attitudes?", International Journal of Contemporary Hospitality Management, Vol. 26 No 4, pp. 629 - 652.

Mincuzzi, A. (2015), “Terremoto su Expo 2015, sette arresti: la «cupola degli appalti», le tangenti, i nomi dei politici” IlSole24Ore, 24 Feb 2015, pp. 1-2.

Minnaert, L., (2012), “An Olympic legacy for all? The non-infrastructural outcomes of the Olympic Games for socially excluded groups (Atlanta 1996-Beijing 2008)”, Tourism Management, Vol. 33 No. 2, pp.361-370.

Morrison, A. (2013). Marketing and Managing Tourism Destinaitions, Routledge, New York.

Müller, M. (2015), "What makes an event a mega-event? Definitions and sizes”, Leisure Studies, Vol. 34 No.6, pp. 627642 ,

Nishitani, K., Kaneko, S., Fujii, H., and Komatsu, S. (2012), “Are firms' voluntary environmental management activities beneficial for the environment and business? An empirical study focusing on Japanese manufacturing firms", Journal of environmental management, Vol. 105 No. 2, pp. 121-130.

Pernecky, T., and Luck, M. (2012), Events, society and Sustainability: Critical and contemporary approaches, Routledge, Oxon.

Phi, G., Dredge, D. and Whitford, M. (2014), “Understanding conflicting perspectives in event planning and management using Q method”, Tourism Management Vol. 40, pp. 406-415. 
Prayag, G., Hosany, S., Nunkoo, R. and Alders, T. (2013), “London residents' support for the 2012 Olympic Games: The mediating effect of overall attitude", Tourism Management, Vol. 36, pp. 629-640.

Ritchie, B.W., Shipway, R., and Cleeve, B. (2009), "Resident perceptions of megasporting events. A non-host city perspective of the 2012 London Olympic Games", Journal of Sport \& Tourism, Vol. 14 No. 2/3, pp. 143-167.

Saarinen, J. (2006), "Traditions of sustainability in tourism studies." Annals of Tourism Research, Vol. 33 No. 4, pp. 1121-1140.

Sherwood, P. (2007), “A triple bottom line evaluation of the impact of special events: The development of indicators. Unpublished Doctoral dissertation. Melbourne: Victoria University.

Thomson, A., Schlenker, K., and Schulenkorf, N. (2013), “Conceptualizing sport event legacy”, Event Management, Vol. 17 No. 2, pp. 111-122.

Tosun, C. (2002), "Host perceptions of impacts: a comparative tourism study”. Annals of Tourism Research, Vol. 29 No. 1, pp. 231-253.

Trierweiller A.C., Severo Peixe, B.C., Tezza, R., Bornia, A.C.and Campos L. (2013), "Measuring environmental management disclosure in industries in Brazil with Item Response Theory", Journal of Cleaner Production, Vol. 47, pp. 298-305.

UN Environment Programme (2012), Sustainable Events Guide, UNEP DTIE Sustainable Consumption and Production Branch, Paris.

UNEP (1987), Our Common Future, Oxford University Press, Oxford.

Williams, C.C., and Millington, A.C. (2004), "The diverse and contested meanings of sustainable development." The Geographical Journal, Vol. 170 No. 2, pp. 99-104.

Winship C. and Mare R.D. (1984), "Regression Models with Ordinal Variables” American Sociological Review, Vol. 49, No. 4, pp. 512-525.

Vargas-Sanchez, A., Porras-Bueno, N., and Plaza-Mejia, M. (2011), “Explaining residents' attitudes to tourism: is a universal model possible?", Annals of Tourism Research, Vol. 38 No. 2, pp. 460-480.

Xiang, R.L., Hsu, C., and Lawton, L. (2015), “Understanding Residents' Perception Changes toward a Mega-Event through a Dual-Theory Lens", Journal of Travel Research, Vol. 54 No. 3, pp. 396-410

Xuan-Quynh L.E., Van-Hieu, V.U., Hens, L. and Heur, B.V. (2014), "Stakeholder perceptions and involvement in the implementation of EMS in ports in Vietnam and Cambodia”, Journal of Cleaner Production, Vol. 64, pp. 173-193.

Zielinski, S. and Botero, C. (2015) Are eco-labels sustainable? Beach certification schemes in Latin America and the Caribbean, Journal of Sustainable Tourism, Vol. 23 No. 10, pp. 1550-1572.

Zhou, Y. and Ap, J. (2009), "Residents' perceptions towards the impacts of the Beijing 2008 Olympic games", Journal of Travel Research, Vol. 48 No. 1, pp. 78-91.

Web links:

http://www.expo2015.org/en/milan-expo-2015--the-first-universal-exposition-with-a-certification-for-event$\underline{\text { sustainability }}$ 